\title{
DESCUBRIENDO LOS PAISAJES DE LEANDRO SILVA DELGADO
}

ANA PAULA RIAL 


\section{ANA PAULA RIAL}

Artista plástica, pertenece a la Fundación de Arte Contemporáneo. Arquitecta, Facultad de Arquitectura Universidad ORT Uruguay. Diplomada en proyecto de paisaje, Universidad de la República. Paisajista, profesional independiente. 


\section{RESUMEN \\ ABSTRACT}

Leandro Silva Delgado (1930, Salto - 2000, Segovia) es el paisajista uruguayo más importante internacionalmente pero casi un desconocido en nuestro país.

Hizo estudios de arquitectura en Montevideo, una pasantía en Rio de Janeiro, con Burle Marx, y estudió paisajismo en Versalles. Comenzó su carrera en Madrid, donde fue el nexo de las nuevas corrientes; y proyectó más de 300 parques y jardines repartidos por el mundo.

De todos estos su obra más personal es su jardín experimental en Segovia, el Romeral de San Marcos, y la más destacada la restauración del Real Jardín Botánico de Madrid.

Volvió a Uruguay frecuentemente, donde llevó a cabo varios proyectos, especialmente en su Salto natal.

No solo se limitó al paisajismo, tuvo una carrera de gran importancia como artista plástico y como docente, ya que formó a toda una generación de paisajistas españoles.

Palabras clave: Uruguay, arquitectura paisajista, arte, Leandro Silva Delgado.

Leandro Silva Delgado (1930, Salto - 2000, Segovia) is the most important Uruguayan landscaper internationally, but almost unknown in our country.

His studies were architecture in Montevideo, did an internship in Rio de Janeiro with the Burle Marx, and studied landscaping at Versailles. He began his career in Madrid where he was the nexus of the new trends and projected more than 300 parks and gardens scattered around the world.

Of these the most personal work is his experimental garden in Segovia, El Romeral de San Marcos and the most prominent the Real Jardin Botánico de Madrid restoration.

He returned to Uruguay frequently, where he carried out several projects, especially in his native Salto. He didn't limit to landscaping, he had a career of great importance as an artist and as a teacher since he trained a whole generation of Spanish landscape architects.

Keywords: Uruguay, Landscape architecture, Leandro Silva Delgado. 


\section{LOS ORÍGENES: ENTRE EL ARTE Y LA ARQUITECTURA}

Silva Delgado nació y vivió hasta su adolescencia en Salto, una ciudad del norte de Uruguay. Recuerda que en su infancia no salía a la calle, jugaba mucho en el jardín y tenía su micromundo de árboles, lianas y tortugas. Se acuerda especialmente del jardín de sus abuelos, una fuente de misterio y admiración donde los olores de la madreselva se mezclaban con los de los jazmines y el color de las flores del jacarandá.

El agua va a ser otro gran recuerdo:

El río Uruguay, marcando el límite de mi ciudad natal con las cercanas costas de la provincia de Entre Ríos. Paisajes parecidos pero distintos, límite entre dos países, entre dos economías, con enormes similitudes pero lógicas diferencias; es decir, un espacio ideal para entender, comparar y sorprenderse ante las características bien diferenciadas de dos países hermanos (Silva Delgado, L, 2001, p. 9).

Estas ciudades del interior del país se caracterizan por su particular manera de entender el tiempo, con un ritmo lento. Quizás por eso Silva Delgado era una persona que no se apresuraba, apreciaba la contemplación, se tomaba un tiempo entre mirar y ver. Esta manera de ser lo ayudó en su vocación de paisajista, porque para trabajar con la naturaleza hay que tener paciencia.

La manera de ser del uruguayo también marcó una manera de proyectar, sin estridencias, respetando a su entorno y con la humildad que le permitiría pasar de ser jardinero a paisajista sin caer en la soberbia aca- démica. Es más, los jardines que admiraba eran los de «rancherío», por donde no había pasado la mano de un paisajista.

Tomó clases de pintura en el taller Horacio Quiroga, donde a los 14 años tuvo como docente a José Cuneo, quien se encontraba pasando una larga temporada en Salto. Este le enseñó cómo enfrentarse «al paisaje, a analizarlo y a descubrir sus grandes líneas. Es muy diferente analizar el paisaje con la palabra o con la discusión más encendida que con el lápiz y el papel y anotando y dibujando» (Silva Delgado, L, 2011, p. 9).

También estudió pintura con Alceu Ribeiro, quien fue su conexión con el taller de Torres García.

Cuando terminó el bachillerato se mudó a Montevideo para comenzar arquitectura, no por convicción sino porque entre las opciones de carreras que había en Uruguay era la que más se acercaba a sus intereses. Cuando su docente Iglesias Chávez le acercó un artículo de Sigfried Gideon sobre Burle Marx, supo al terminar de leerlo que ser paisajista era su irremediable vocación.

Por otro lado, como pintor Silva Delgado era una joven promesa, luego de comenzar como artista figurativo se volcó a la abstracción y fue admitido en el Salón Nacional a los 22 años. Fue parte del envío de Uruguay a la Bienal de Arte en San Pablo en la III y la V edición, lo cual le permitió conocer personalmente a Burle Marx, quien estaba presentando unos jardines en la sección arquitectura.

Roberto Burle Marx es el máximo exponente del paisajismo moderno, era una combinación entre artista 
plástico, naturalista y paisajista. Brasileño de padres europeos, fue en una visita a Alemania en 1928 cuando tomó contacto con las vanguardias y conoció en el jardín botánico de Berlín un invernadero de flora brasileña donde se dedicó a pintarla. Cuando regresó a Brasil empezó a crear jardines con una combinación de diseño gráfico, colores primarios al estilo neoplástico, y formas orgánicas. La conexión entre sus pinturas y los jardines es impresionante. Pocas especies, mucha repetición, y grandes manchas de color son sus pilares estéticos.

Pero el gran aporte de Burle Marx fue que recolectó, clasificó y multiplicó plantas nativas brasileñas desconocidas hasta el momento, además de otras en peligro de extinción. Luego estudió los hábitos de coexistencia entre las plantas para incorporarlas como ornamentales en el diseño de sus jardines, que antes solo se hacían mayoritariamente con especies introducidas. En este proceso fue de los primeros ambientalistas que denunciaron la desforestación de la Amazonia brasileña.

Su colaboración con los grandes arquitectos del modernismo brasileño, Lucio Costa y luego Oscar Niemeyer, le dio a sus jardines visibilidad y reconocimiento mundial. El edificio Gustavo Capanema, en Rio de Janeiro, en especial marca un hito en la arquitectura modernista de Brasil, y genera un quiebre en el paisajismo mundial, con sus formas libres en los canteros de las terrazasjardines, los espacios de contemplación o de estar y el uso de vegetación nativa y exuberante.

Conocí sus colecciones de aráceas. Su fervorosa pasión por la flora brasileña. Su personalidad de pintor y de fino dibujante. Regresé a Uruguay. Mi vocación por la pintura se fortaleció. Había descubierto en la jardinería un ámbito amplio y sugestivo en el cual me sentí definitivamente comprometido (Silva Delgado,

L, 1987, p. 3).

Abandonó la carrera de arquitectura en tercer año y realizó luego una extensa pasantía en el taller de paisajismo de Burle Marx, convirtiéndose en uno de sus alumnos predilectos y en amigo personal. Burle Marx le recomendó trabajar el lado botánico científico y conocer a las plantas, la materia prima de sus creaciones.

\section{EL NÓMADA: ENTRE LA MODERNIDAD Y LA TRADICIÓN}

En abril de 1959 viajó a Estados Unidos con un grupo de estudiantes de arquitectura y conoció la obra de Frank Lloyd Wright, quien había fallecido recientemente. En Berkeley entró en contacto con conceptos de diseño basados en aspectos ecológicos y ambientales, muy distintos al tipo de diseño europeo, más formal y visual.

En los sesenta decidió emigrar a Europa buscando perfeccionarse como paisajista, y consiguió una beca para cursar la Escuela Nacional Superior de Paisaje de Versalles. Luego trabajó en esta escuela como docente con Jacques Sgard. Vivir en Francia le permitió hacer nuevos contactos y viajar para conocer paisajes de Inglaterra, Holanda e Italia, donde quedó especialmente maravillado con los jardines renacentistas.

En el área pictórica continuó pintando y comenzó a estudiar grabado en el atelier Bersier, de la Escuela de Bellas Artes de París, una de las más tradicionales. 


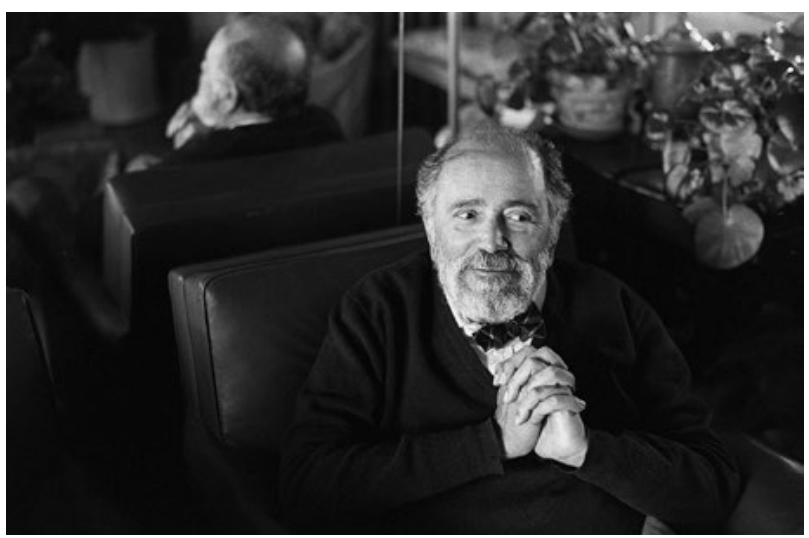

01.

Retrato.

FOTO: PANTALEÓN ASTIAZARAN. 1996

02.

Estudio paisajístico del Centro Turístico Deportivo, Murcia.

LEGADO SILVA.

03

Parc des Floralies, Bois de Vincennes, París.

LEGADO SILVA.

Participó en una muestra colectiva en el Museo de Arte Moderno e hizo dos exposiciones personales.

Esta etapa de aprendizaje y perfeccionamiento finalizó con el encargo del Servicio Técnico de Parque de Jardines del Ayuntamiento de París de elaborar un proyecto para el parque floral de Vicennes, junto a Jacques Sgard y Alain Provost. Era un proyecto de grandes dimensiones que le permitió llevar sus ideas pictóricas al paisaje, creando lomas con grandes manchas de color -que incorporó mediante flores- que sostienen esculturas. La idea más importante que maduró en este proyecto es que el movimiento de tierra y el modelado del suelo es fundamental,

[...] la esencia de la estructura del jardín. Árboles y arbustos, macizos de flores vendrían a comentar 0 simplemente acentuar lo propuesto anteriormente por el movimiento de tierras. Considero totalmente incorrecto pretender corregir o disimular con plantas los problemas que han quedado pendientes al reestructurar la topografía de nuestro nuevo paisaje (Silva Delgado, L, 1987, p. 3).

El año 1969 fue cuando dio por terminada su etapa de estudios y decidió volver a Uruguay a ejercer su profesión, pero esta posibilidad no parecía muy clara en este país, dadas las circunstancias que se vivían, por lo que decide volver a emigrar buscando un nuevo destino donde poder trabajar como paisajista.

\section{EL MENSAJERO. DE AMÉRICA A EUROPA}

Eligió España, específicamente Madrid, para instalarse, por amistades, por su clima y por las ciudades cercanas, entre ellas Toledo, Aranjuez y Segovia. Llevó las ideas del paisajismo biomórfico de Burle Marx a España, mezclándolas con la influencia que ejercen los jardines hispanoárabes.

Cabe aclarar que el concepto de paisajista en España no estaba muy claro, se lo confundía con pintor de paisajes, pero era una actividad que él definía como «la tarea de ordenar y reinventar» su entorno. No había una actividad formal, así que fue creador y docente de la Escuela de Jardinería y Paisajismo Castillo de Batres, por mucho tiempo la única que ofrecía un curso completo de paisajismo, y luego enseñó en la Universidad Menéndez Pelayo y en el Círculo de Bellas Artes.

Uno de sus primeros encargos de esa época lo recibió del escultor Pablo Serrano, quien estaba haciendo un monumento para el ayuntamiento de Las Palmas, a instalarse en la plaza Pérez Galdós, quien puso como condición para terminar su trabajo que Silva Delgado diseñara el entorno paisajístico. Juntos diseñaron una plaza que rompía con el modelo de las típicas plazas es- 


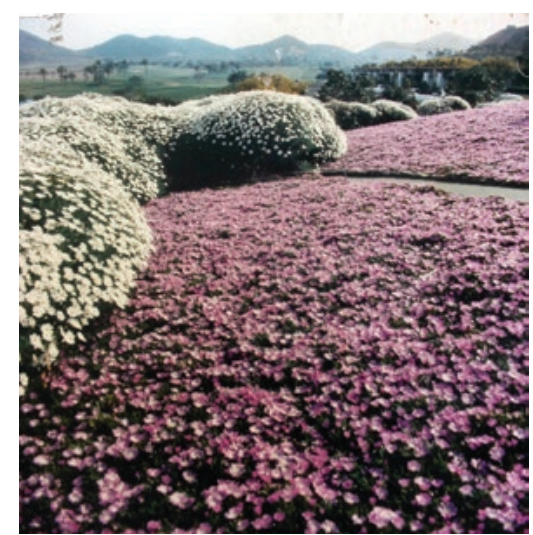

02.

pañolas, muy cuestionado en su etapa de proyecto pero con un exitoso resultado final.

Participó en el concurso de la Plaza de Colón como paisajista en un equipo multidisciplinario junto con el arquitecto urbanista Juan Orbe, el escultor Jorge Oteiza y el pintor Joan Miró, entre otros. Ganaron el primer premio, el cual fue pagado, pero en la materialización los técnicos municipales distorsionaron el proyecto original hasta borrarlo. Estos sinsabores de la profesión le tocarán varias veces en su carrera, por ejemplo en un proyecto de un jardín para ciegos que, pese a que no se construyó, tuvo en él un gran impacto como proyectista, porque buscó maneras de exacerbar los otros sentidos.

De esa manera fui descubriendo las numerosas variaciones a las que se puede llegar simplemente con el cambio de textura de los senderos de un jardín, la arena, el césped, la gravilla, el cemento... Ilegando así a la identificación de cada ámbito simplemente a través de la sensación producida por el suelo que se pisa. Las zonas frescas y sombreadas, las abiertas y cálidas, la textura de las hojas y las ramas, la elección de las especies utilizadas en setos y masas arbustivas, tan en contacto con el usuario del jardín, me permitieron controlar y modelar texturas a veces muy suaves y flexibles y otras veces más duras e hirsutas. El sonido del follaje de las diferentes especies arbóreas como parámetro ambiental me ha llegado a interesar hasta la obsesión. Todo lo que va desde el

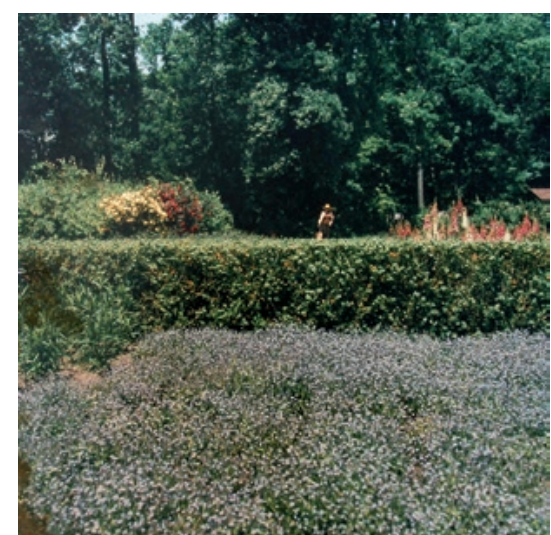

03.

sonido del viento en un grupo de pinos o casuarinas hasta el alegre roce de las hojas de los álamos, o el ruido de la lluvia sobre un filodendro o un bananero, debe estar rigurosamente controlado (Silva Delgado, L, 1987, p. 6).

Sin lugar a dudas, uno de sus trabajos más importantes fue la restauración del Real Jardín Botánico de Madrid, prueba de la determinación y paciencia de Silva Delgado. Este jardín botánico se había construido en 1780 bajo el reinado de Carlos III, en un terreno de una gran pendiente, que permitiría exponer todas las especies del nuevo mundo. El jardín se encuentra enclavado en un ámbito urbanístico que comprende al Museo de Ciencias Naturales (hoy Museo del Prado), la Colina de las Ciencias, el Observatorio Astronómico y el propio Real Jardín.

El lugar cargaba con una historia complicada y un futuro incierto: se hablaba de hacer un proyecto de un gran jardín botánico en las afueras de Madrid, y se había dejado abandonado este en medio de la ciudad. También se proponía para este predio un proyecto de museo dedicado enteramente a Goya, con lo cual el jardín se hubiera reducido a un anillo exterior verde.

En este limbo hubo una serie de malas decisiones y malos asesoramientos, y se llegó a un punto en que 


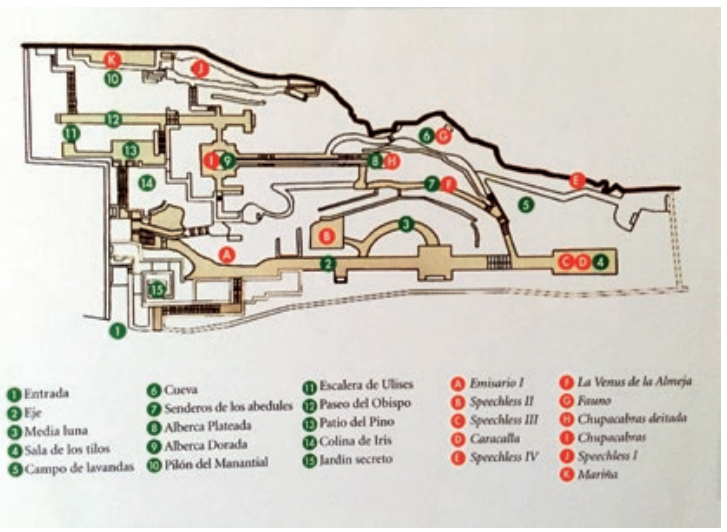

04.

se decidió cerrar el museo. En este contexto, en 1977 el Consejo Superior de Investigaciones Científicas encargó a Silva Delgado un informe paisajístico. Para cumplir con ello consiguió unos fondos monetarios para intentar restaurar una pequeña parcela, y allí descubrió unas fuentes y vislumbró un resto de las trazas del diseño original a rescatar.

Fue tal el éxito de la primera etapa que a esta le sucedić una segunda, y una tercera, hasta acondicionar el predio completo de nueve hectáreas en ocho años. Una de las conclusiones a las que llegó fue que por 1875 se había querido transformar el lugar en un jardín inglés, y para eso se había rellenado con 70 u 80 centímetros de tierra, lo cual enterró caminos, senderos, escalones y fuentes. Silva Delgado se transformó en un metódico investigador histórico, casi arqueólogo, buscando el diseño original perdido por 200 años y restaurándolo con rigurosidad científica. También hizo intervenciones como paisajista, pero muy respetuosas de la historia y con una impronta que se repite en la obra de Silva Delgado: da la impresión de que el paisaje siempre estuvo ahí.

De todo este proceso lo que más le llamó la atención a Silva Delgado fue que nadie se acordaba de cómo había sido este jardín, cómo en 200 años había desaparecido de la memoria colectiva, lo efímero de las construccio-
04

Planos de vegetación del Romeral de San Marcos, plano general.

REALIZADO POR LUISA ROQUERO, MARÍA JESÚS CAGIGA, MARÍA GRIS Y JUAN PEDRO SACEDÓN. LEGADO SILVA.

05.

\section{Fotografías del Romeral de San Marcos, Segovia: recorrido por el jardín.}

COLABORADORES: LUISA ROQUERO Y JUAN PEDRO SACEDÓN. LEGADO SILVA.

06.

\section{Jardines de la Torre Picasso, Madrid.}

LEGADO SILVA.

nes verdes. En 1982 se inauguró con la presencia del rey Juan Carlos, hecho que le dio legitimidad a su carrera en España.

Entre numerosos encargos de proyectos de parques y jardines privados resalta uno por su dimensión: las 40 hectáreas del Parque Lineal de Palomeras, en Vallecas. Este proyecto logra una transición entre un conjunto habitacional para 12 mil familias y la autopista M-40, disponiendo un proyecto más estructurado cerca de los edificios que se transforma en uno más silvestre junto a la ruta. Silva Delgado construyó allí una serie de colinas (aprovechando los escombros de la construcción y abaratando así los costos de transporte del relleno) donde se puede ver el campo «suavemente ondulado» de Uruguay que hace de «biombo» antes de la autopista, una de las más transitadas y ruidosas de Madrid. Logra generar espacios a escala humana en una serie de senderos, espejos de agua y bosquecillos naturalizados que hacen creer que siempre estuvieron ahí, utilizando solo plantas resistentes y autóctonas.

También se pueden destacar los jardines de la Torre Picasso, donde no había espacio para plantar nada con grandes raíces debido al cemento; allí construyó unas esferas de metal verde que forró con enredaderas, construyendo un verde geométrico muy particular. Además 


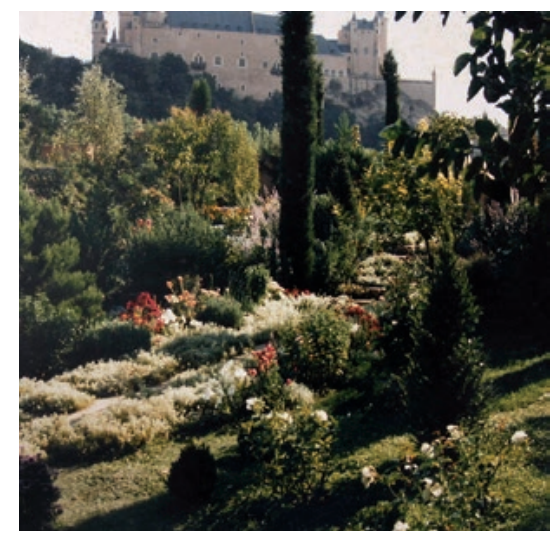

05.

muchos jardines de Silva desarrollaron la tendencia biomórfica, tan presente en la obra de Burle Marx, con las necesarias adaptaciones a un medio y un momento distintos. Junto con él y Michel Viollet realizó el proyecto de la Cité Scolaire du Port, para la isla Reunión.

Silva Delgado pensaba que la conservación del jardín era igual o más importante que el proyecto; y ya que el cliente es quien definirá su destino, es necesario que este participe en el proceso de diseño. Por esa razón es difícil trabajar con organismos estatales o corporaciones, donde no está claro quién es el comitente.

En su faceta de artista plástico incorporó la acuarela, que empezó a usar como herramienta para sacar apuntes rápidos en viajes y terminó siendo una técnica usada sola o en collage con papeles e hilos. Silva Delgado hallaba una satisfacción en la pintura que el paisajismo no le daba: la inmediatez de su conclusión.

\section{EL EXPERIMENTO: EL ROMERAL DE SAN MARCOS}

En 1973 Silva Delgado y su mujer, Julia Casaravilla, decidieron comprar un terreno para tener una casa de fin de semana en las afueras de Madrid, y encontraron un singular espacio en Segovia.

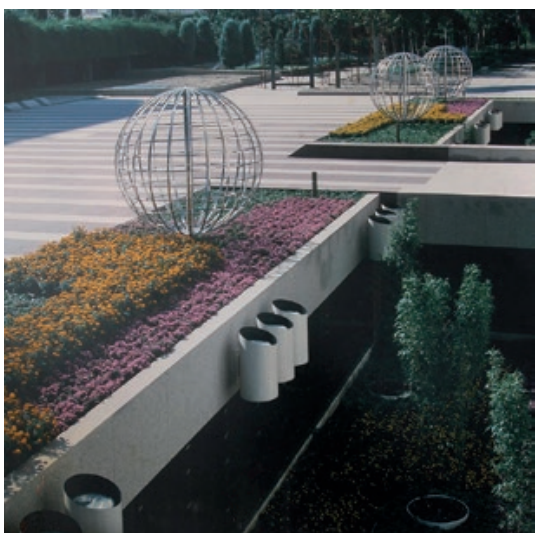

06.

Hace un cuarto de siglo, aproximadamente, se me presentó la ocasión de adquirir un huerto en el arrabal de San Marcos, en la ciudad de Segovia. Se trataba de una superficie de media hectárea orientada al mediodía y protegida de los fríos del norte por un dramático conjunto de rocas calizas. Desde allí se podía descender a través de varios bancales a la zona más baja del terreno muy próxima al curso del río Eresma. Las vistas hacia el sur describían el perfil del casco antiguo de la ciudad de Segovia (Silva Delgado, L, 2001, p. 13.).

Este terreno se convertiría en el Romeral de San Marcos, el jardín experimental donde Silva Delgado aplicaría los conceptos que fue desarrollando en su carrera, con la libertad de ser el comitente, al mejor estilo del jardín de Santo Antônio da Bica, de Burle Marx.

En el terreno había dos casitas de pueblo muy rústicas, donde hicieron un refugio y su taller de grabador mientras armaban el jardín, y más tarde las reacondicionaron como casas de fin de semana. En la conferencia «El arte y la ciencia en el desarrollo del patrimonio paisajista», dictada en el V Seminario Internacional de Arquitectura Paisajística, realizado en noviembre de 1999 en la ciudad de La Plata (Buenos Aires, Argentina), Silva Delgado expone todo el proceso creativo y formal del jardín, donde muestra su peculiar sensibilidad por el entorno y el valor de la investigación histórica. 


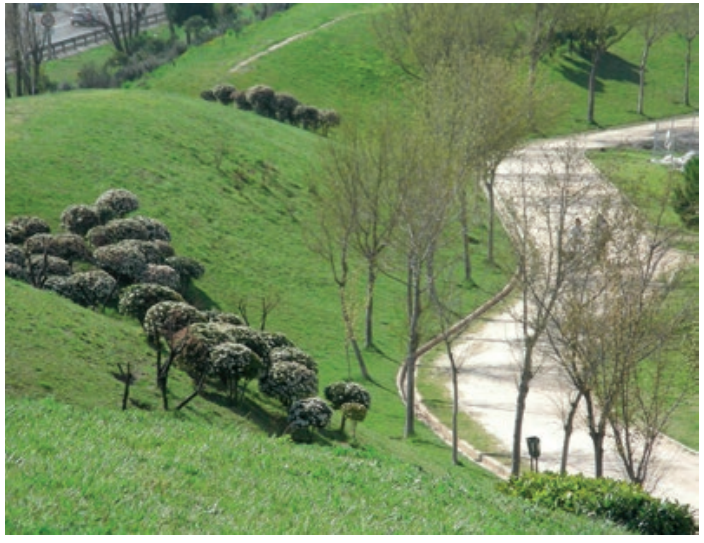

07.

El Alcázar de Segovia es un castillo-fuerte que se alza en el cerro lindero, y es tal la magnitud de su presencia que llegaba a dominar el paisaje. Con el correr del tiempo, y cuando los árboles crecieron lo suficiente, el Alcázar pasó a ser una más entre las sorpresas y misterios que encierra el jardín.

Este era un huerto abandonado donde solo crecía vegetación sencilla, como el romero y el tomillo; comenzó estudiando lo que había en los terrenos vecinos, y comprobó que entre los cipreses, álamos y sauces eran posibles varios frutales y arbustos más delicados, como el boj y la rosa. Cuando terminó este inventario comenzó a incorporar otras especies que deberían ir bien, como el Viburnum tinus para los cercos y el Hipericum. Probando, con aciertos y errores, Silva Delgado incorporó 300 especies, oficiando no solo como paisajista sino también como jardinero durante 30 años.

Pero el éxito del jardín no se debe a la supervivencia vegetal: el terreno tiene una gran pendiente que fue salvada mediante terrazas que se fueron articulando con caminos, senderos y escaleritas que confluyen en pequeñas plazoletas y lugares de estar, con unos trazados geométricos muy rigurosos. Utilizó los materiales que tenía a mano, la piedra y el revoque. El agua mana naturalmente de algunos manantiales, y Silva
07.

\section{Parque Palomeras, Madrid.}

FOTO: JOSÉ MANUEL GARCÍA VALLÉS. 2010.

CON PERMISO DEL AUTOR

08.

PÁGINA OPUESTA

Parque del Descubrimiento, Salto, 2011.

PÁGINA OFICIAL DE FACEBOOK DE LEANDRO SILVA

Delgado la embalsó en algunos lugares y también le dio movimiento, llevándola de un lado a otro mediante acequias, evocando los jardines hispanoárabes.

El conocimiento de algunos jardines del mundo musulmán al que he ido accediendo a través de mis viajes a Andalucía y a Mallorca, donde trabajo en forma regular y constante desde hace quince años, [...] he tenido ocasión de constatar la vigencia y el ajuste de los elementos de la composición de los jardines hispano-musulmanes. Marruecos primero y Arabia Saudita después fueron completando esta experiencia. Fue así como le he dado todo su valor al sonido del agua de los surtidores pero también al perfume de la rosa y del jazmín, del mirto y del romero, por ejemplo (Silva Delgado, L, 2001, p. 13).

Silva Delgado incluyó sensaciones para todos los sentidos, como había proyectado en su jardín para ciegos: para la vista, con la explosión de color de las flores en verano, los perfumes para el olfato, los lugares de sol y sombra, los caminos, y siempre dejando algún rincón para descubrir, creando un halo de misterio que no nos deja ver adónde nos llevan los senderos.

San Marcos se convirtió en una escuela para sus alumnos, donde hacía recorridos en primavera y otoño. En 1995 los Silva Delgado se retiraron al Romeral, que pasó a ser su domicilio permanente. 
to.

4.

an $=$

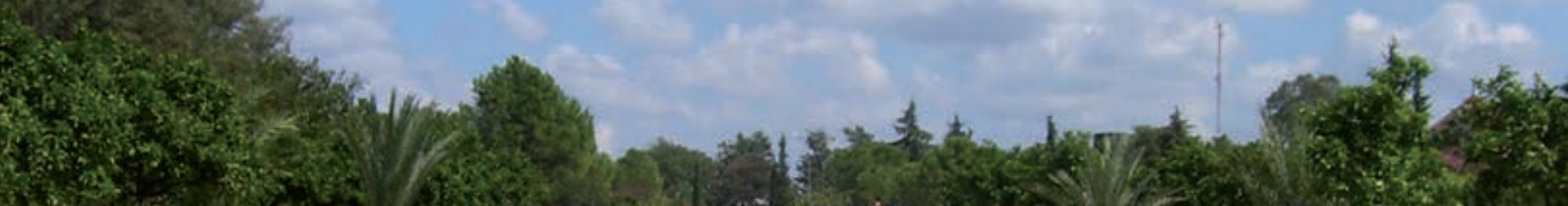

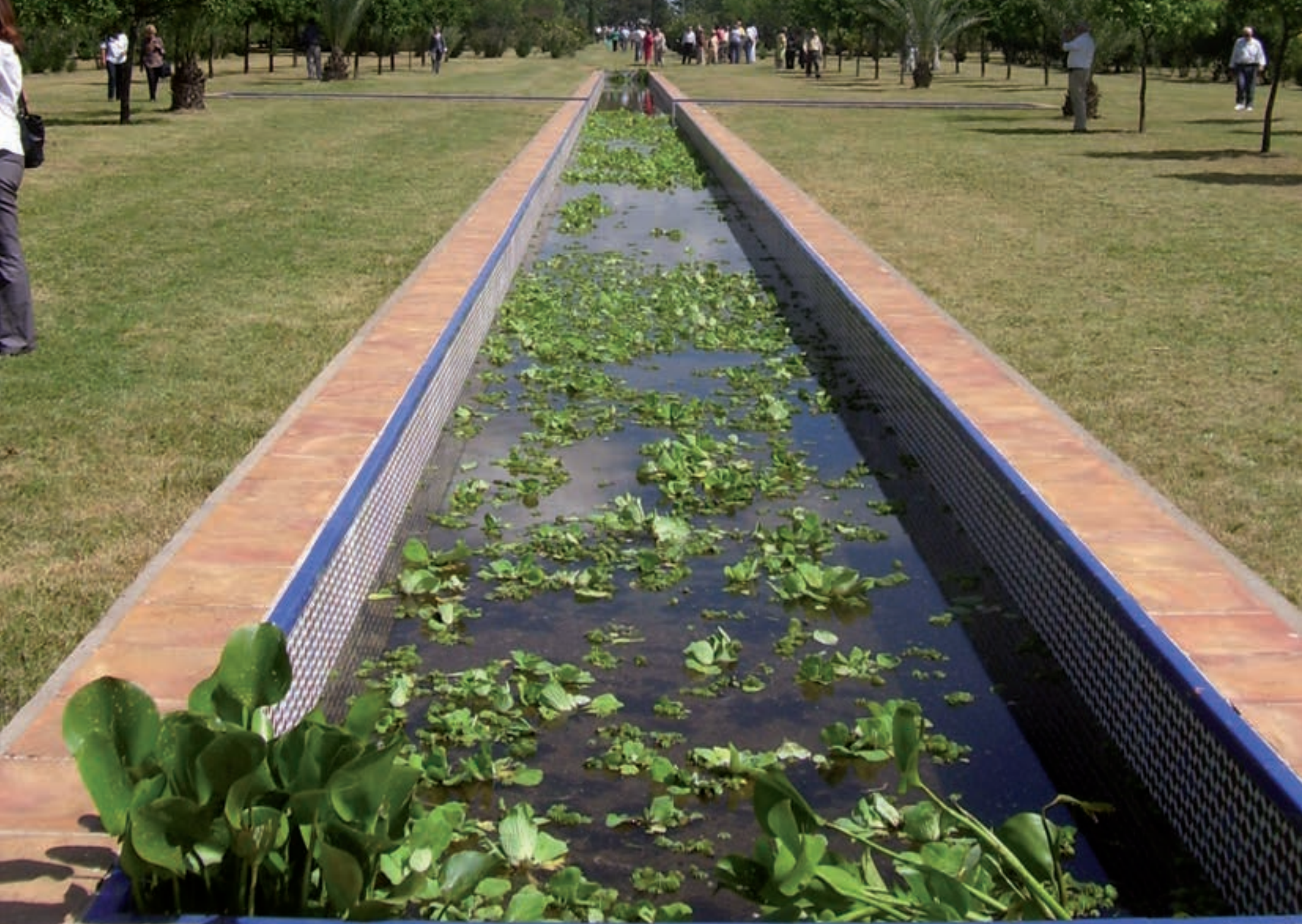

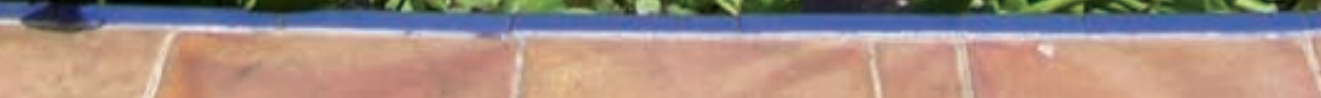




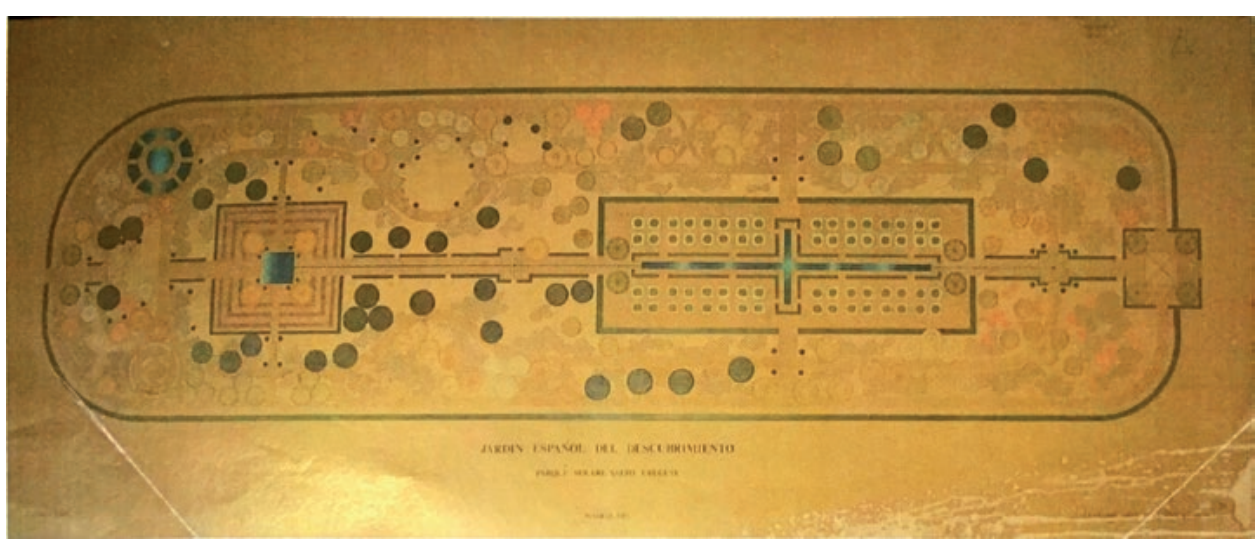

०9.

\section{VOLVIENDO A URUGUAY: IMÁGENES BORROSAS}

Cuando se restableció la democracia Silva Delgado pudo trabajar en Uruguay, y se aseguró de venir asiduamente ya que era consciente de que su imagen profesional no coincidía con su trabajo, se pensaba que solo era pintor de cuadros. Uno de sus primeros encargos fue asesorar al primer presidente posdictadura, Julio María Sanguinetti, en el reacondicionamiento de la estancia presidencial de Anchorena, en el departamento de Colonia.

Su obra de más importancia en Montevideo es el jardín del Museo Nacional de Artes Visuales, que venía reformándose desde la década del 70 bajo la dirección del arquitecto argentino Clorindo Testa. Por 1990 Silva Delgado y el arquitecto Fernando Fabiano proyectaron el jardín frontal, donde había «un piso de madera, cuatro patios de esculturas y fuentes forradas de mármol con agua corriente, pero todo quedó sin terminar». Silva Delgado entró en cólera cuando descubrió la reja que se le había adosado al jardín -aparentemente obra de Testa- y con la mayoría de los desajustes que se deberían a temas de presupuesto del Ministerio de Educación y Cultura, que era el que proveía los recursos.

En Salto planeó la restauración del parque Solari con la misma impronta del Real Jardín Botánico de Madrid; el lugar estaba clausurado y a nivel gubernamental se proponía una tala generalizada. La señora Isidra Solari le escribió una carta a Silva Delgado y le pidió un proyecto para revitalizar el parque, para replantarlo.

\footnotetext{
Hacía muchísimos años que no lo veía, y él estaba triunfando en Europa. Me contestó con una carta de lo más emotiva, diciéndome que él había iniciado su vocación jardinera en el parque Solari, que lo recordaba perfectamente, y en esa carta lo describe todo, sus sombras, los perfumes resinosos de sus cipreses, y que estaba dispuesto a hacer un proyecto, y así lo hizo (Silva Pinasco, L, 2008, p. 1.).
}

Silva Delgado propuso restituir las especies que se adecuaran al diseño original del parque, estilo romanticista.

Al norte del parque proyectó, en un área de dos hectáreas, un jardín Ilamado Jardín del Descubrimiento (hoy renombrado parque Silva Delgado), para conmemorar los 500 años del descubrimiento de América, donde se plantarían todas las especies que trajeron los españoles a América. Siguiendo esa idea, pero en espejo, logró interesar al embajador de España y pudieron hacer un parque en Andalucía, en la ciudad de Motril, que cuando lo inauguraron se llamaba Jardín del Descubrimiento (hoy lleva el nombre de Parque de los Pueblos de América) y que, a la inversa del salteño, está poblado de especies de América. 
09.

\section{Plano del Parque del Descubrimiento, Salto.}

ARCHIVO DEL ARQUITECTO PAISAJISTA FERNANDO BRITOS.

10

Jardines del MNAV, Montevideo.

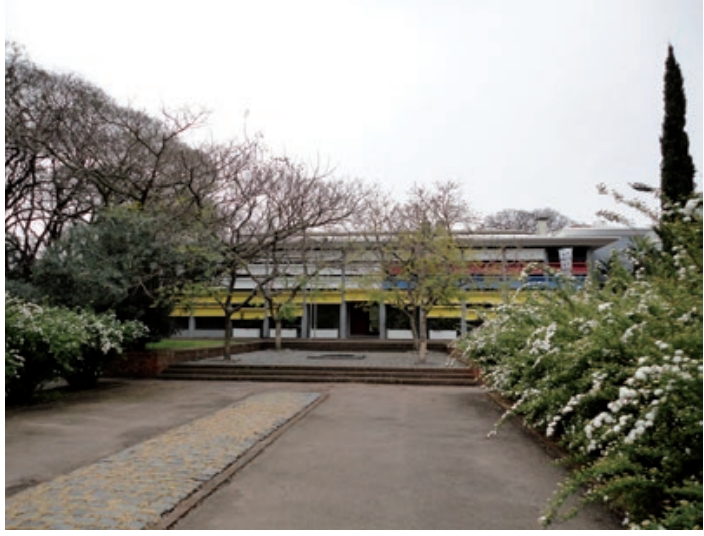

10.

En 1986 se puso la piedra fundamental en Salto, se avanzó durante cinco años con la nivelación y construcción de muros de contención, pero la obra se interrumpió entre 1990 a 1995 y en ese lapso se perdieron muchas de las especies traídas de Europa.

En noviembre de 2000 Silva Delgado falleció en el Romeral. Sus cenizas fueron esparcidas en su Salto natal y en su jardín de Segovia, donde vivió rodeado de todas las plantas que le recordaban a su infancia. Según sus propias palabras, «El jardín nace de la nostalgia producida por la pérdida del paraíso», y así está escrito en el folleto que los organismos de fomento del turismo de Segovia elaboraron para promover la visita al Romeral.

\section{EL LEGADO}

La obra pictórica de Silva Delgado sobrevive en colecciones privadas y museos. También sus ideas, en la obra de sus alumnos, en quienes influyó por más de tres décadas como docente; incluso algunos han escrito libros sobre su maestro.

Una de sus ideas más relevantes fue la creación de un sistema de proyecto que involucra, aparte de las coordenadas geométricas, la dimensión del tiempo, llamado «perceptogramas», que prevé todos los matices a darse por la vegetación en una época dada del año.
Sus jardines tienen un carácter efímero que hace su existencia muy frágil. En el Romeral, su viuda, Julia Elena Casaravilla, cuida el jardín en el que reside, abierto al público y donde se hacen jornadas conmemorativas, como la Fiesta del Lirio, cada mayo, y una instancia de puertas abiertas en noviembre, recordando a Silva Delgado. Hubo un acontecimiento especial en 2012 llamado «El jardín de las delicias: el Romeral de San Marcos, de Leandro Silva, intervenido por Francisco Leiro», un escultor que con su obra reconfiguró el espacio del jardín.

Sus papeles personales, la colección de sus apuntes, dibujos, planos y documentos relativos a viajes y visitas de obra fueron donados a la Escuela Técnica Superior de Arquitectura de Madrid, donde se conservan en un archivo que ha sido catalogado en 2008 con rigurosidad científica. Este proyecto ha desencadenado exposiciones, entre ellas una en 2011 titulada Imaginar jardines. El legado de Leandro Silva en la ETSAM, que ha sido itinerante, mostrando su obra a distintos públicos.

Mientas en Madrid se trata de digitalizar su archivo para que pueda ser consultado por el mayor número de personas posible sin que esto suponga su deterioro, y se le pone su nombre a una calle como reconocimiento, en Montevideo se sigue desmereciendo la obra de Silva Delgado. Las fuentes del jardín del MNAV no tienen el 


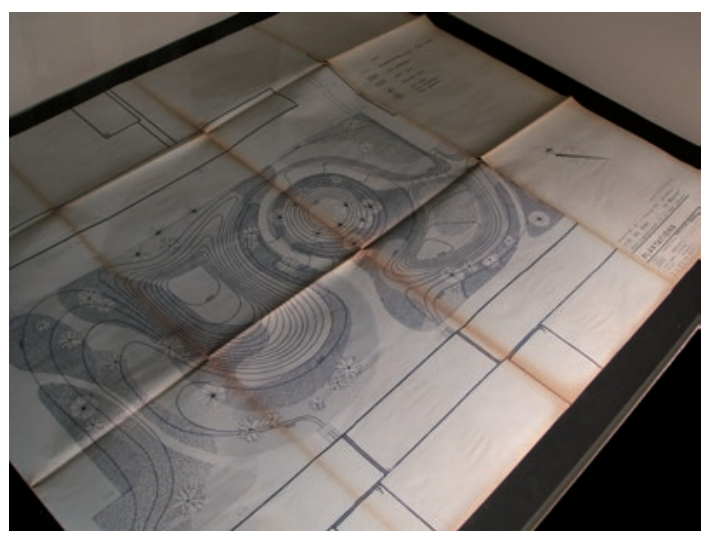

11.

agua que, según sus propias palabras, «debería reflejar el cielo»; y se han hecho reformas que poco tienen que ver con el espíritu original del jardín, es más, no se sabe con certeza cómo era el proyecto original, y la poda del jardín no hace más que desmerecerlo.

Silva Delgado dejó varias ideas y proyectos inconclusos, entre ellos la recreación de la costa del Río de la Plata que va desde Punta del Este hasta Carmelo y un par-
11.

Plano colección biblioteca.

LEGADO SILVA.

que indígena, la recuperación de los arroyos de Salto y la incorporación de arbolado urbano específico para su ciudad. Silva Delgado merece igual reconocimiento en su tierra que el que logró en Europa; esperemos que sus sueños para Uruguay se materialicen y sea recordado por su pueblo como un visionario.

RECIBIDO: 10 de noviembre de 2015. ACEPTADO: 1 de diciembre de 2015 . 


\section{BIBLIOGRAFÍA}

Con la colaboración del material bibliográfico y de archivo del arquitecto paisajista Fernando Britos.

ARLINGTON, V. \& LABORDE, G. (1996). «Con Leandro Silva Delgado, un artista en flor», en revista Tres. Montevideo, pp. 37-39.

ANIBARRO RODRÍGUEZ, M. \& SANZ HERNANDO, A. (2011). EI legado de los arquitectos. Leandro Silva Delgado. Madrid, pp. 120-127. Recuperado de http://polired.upm.es/index. php/textosdispersos/article/view/1945

AGUIRRE DE URCOLA, I. (2012). «La esencia del jardín, el legado de Leandro Silva Delgado.» Folleto exposición. Santiago de Compostela. Recuperado de https://issuu com/biblioteca-cgac/docs/folletoleandrosilva/1

ÁlVAREZ BASSO, C. \& GÓMEZ MUNICIO, J. (2008). El jardín de las delicias. El Romeral de San Marcos de Leandro Silva intervenido por Francisco Leiro. Sociedad Estatal de Conmemoraciones Culturales. Madrid. p. 124.

KALEMBERG, Á. \& SILVA DELGADO, L. (1987). Leandro Silva Delgado. Exposición retrospectiva. Museo Nacional de Artes Visuales, Montevideo.

AA. VV. (2002). «El Romeral de San Marcos: un jardín de Leandro Silva.» Caja Segovia. Segovia: España.

DI MAGGIO, N. (2000). «Leandro Silva Delgado, el paisajista». en diario El País. Montevideo, p. 36.

GIURIA, B. (1994). «Un paisajista uruguayo está modelando Europa», en revista First. Montevideo, pp. 60-65.

GRILLO, M. (1990). «El mundo como un jardín», en semanario Brecha. Febrero. Montevideo, pp. 20-21.

HERES, A. (2006). «Leandro Silva Delgado, paisajista», en Cuadernos de Arquitectura del Paisaje, vol. 5. Montevideo, pp. 12-21.
MADRI+D (s.f.) «Real Jardín Botánico: arquitectura». Recuperado de http://www.madrimasd.org/ cienciaysociedad/patrimonio/lugaresdelsaber/jardin_ botanico/arquitectura.asp

MARTíN, A. (16 de noviembre 2000). «Fallece Leandro Silva, maestro de los paisajistas españoles», en El País. Madrid.

POLLERI, A. (1987). «Arcadia para todos», en semanario Brecha. Agosto. Montevideo, p. 27.

SANZ HERNANDO, A. \& SUÁREZ MENENDES, M. (2011). «La memoria del paisaje. Organización y gestión del legado del paisajista Leandro Silva Delgado», en Quintas Jornadas Archivo y Memoria. Madrid.

SCHECK, N. (1996). «ardines construidos de sueños, nostalgias y recuerdos», en revista Jardines, de El País. Montevideo, pp. 2-6.

- (1995). «Entre amigos, con los Silva Delgado», en revista Jardines, de El País. Octubre. Montevideo, pp. 10-12.

- (1994). «No tenía una sola célula vulnerable», en revista Jardines, de El País. Montevideo, pp. 2-4.

SILVA DELGADO, L. (2001). «La creación de un jardín experimental en Segovia. La plantación en una zona de calizas cretácicas en Castilla.» Laboratorio de Investigaciones del Territorio y el Ambiente (LINTA). La Plata, pp. 9-13. Recuperado de http://digital.cic.gba.gob. ar/handle/123456789/1290. ISBN 987-98485-0-0

SILVA PINASCO, L. (2008). «Con la señora Isidra Solari», en diario El Pueblo. Salto. Recuperado de http://blogs. montevideo.com.uy/blognoticia_19513_1.html 


\section{FUENTES DE IMÁGENES}

02-06. Legado Silva. Colección digital. Biblioteca Universitaria, Unidad Politécnica, de Madrid. http://biblioteca.aq.upm.es/biblioteca_digital/ especiales/silva.html

08. Página oficial de Facebook de Leandro Silva. https://www. facebook.com/leandrosilvad/photos/a.119144816829.13072 $9.76071921829 / 119145676829 /$ ?type=3\&theater

o9. Archivo del arquitecto paisajista Fernando Britos.
10. http://mnav.gub.uy/graficos/jardino4XX.jpg

11. Legado Silva. Colección digital. Biblioteca Universitaria, Unidad Politécnica, de Madrid. http://biblioteca.aq.upm.es/biblioteca_digital/ especiales/silva.html 